\title{
Modeling of failure mode in knee ligaments depending on the strain rate
}

\author{
Mija Lee ${ }^{* 1}$ and William Hyman ${ }^{2}$
}

Address: ${ }^{1}$ Mija Lee Biomedical Engineering Program, Texas A\&M University, 233 Zachry Engineering Center, M.S. 3120 College Station, Texas 77843-3120 and ${ }^{2}$ William Hyman Biomedical Engineering Program, Texas A\&M University, 233 Zachry Engineering Center, M.S. 3120 College Station, Texas 77843-3120

E-mail: Mija Lee* - mjlee@tamu.edu; William Hyman -w-hyman@tamu.edu

${ }^{*}$ Corresponding author

Published: 17 january 2002

BMC Musculoskeletal Disorders 2002, 3:3

This article is available from: http://www.biomedcentral.com//47/-2474/3/3

(C) 2002 Lee and Hyman; licensee BioMed Central Ltd. Verbatim copying and redistribution of this article are permitted in any medium for any purpose, provided this notice is preserved along with the article's original URL.
Received: 27 September 2001

Accepted: 17 January 2002

\begin{abstract}
Background: The failure mechanism of the knee ligament (bone-ligament-bone complex) at different strain rates is an important subject in the biomechanics of the knee. This study reviews and summarizes the literature describing ligament injury as a function of stain rate, which has been published during the last 30 years.

Methods: Three modes of injury are presented as a function of strain rate, and they are used to analyze the published cases. The number of avulsions is larger than that of ligament tearing in mode I. There is no significant difference between the number of avulsions and ligament tearing in mode II. Ligament tearing happens more frequently than avulsion in mode III.

Results: When the strain rate increases, the order of mode is mode I, II, III, I, and II. Analytical models of ligament behavior as a function of strain rate are also presented and used to provide an integrated framework for describing all of the failure regimes. In addition, this study showed the failure mechanisms with different specimens, ages, and strain rates.

Conclusion: There have been several a numbers of studies of ligament failure under various conditions including widely varying strain rates. One issue in these studies is whether ligament failure occurs mid-ligament or at the bone attachment point, with assertions that this is a function of the strain rate. However, over the range of strain rates and other conditions reported, there has appeared to be discrepancies in the conclusions on the effect of strain rate. The analysis and model presented here provides a unifying assessment of the previous disparities, emphasizing the differential effect of strain rate on the relative strengths of the ligament and the attachment.
\end{abstract}

\section{Background}

The knee is one of the most commonly injured joints. The stability of the knee is dependent on several muscles, the meniscus and four major ligaments. These knee ligaments are the medial collateral ligament (MCL), the lateral col- lateral ligament (LCL), the anterior cruciate ligament $(\mathrm{ACL})$, and the posterior cruciate ligament (PCL).

The effect of strain rate on the failure modes of the boneligament-bone complex has been investigated. There are three failure mechanisms $[1,2]$. The first is midsubstance 


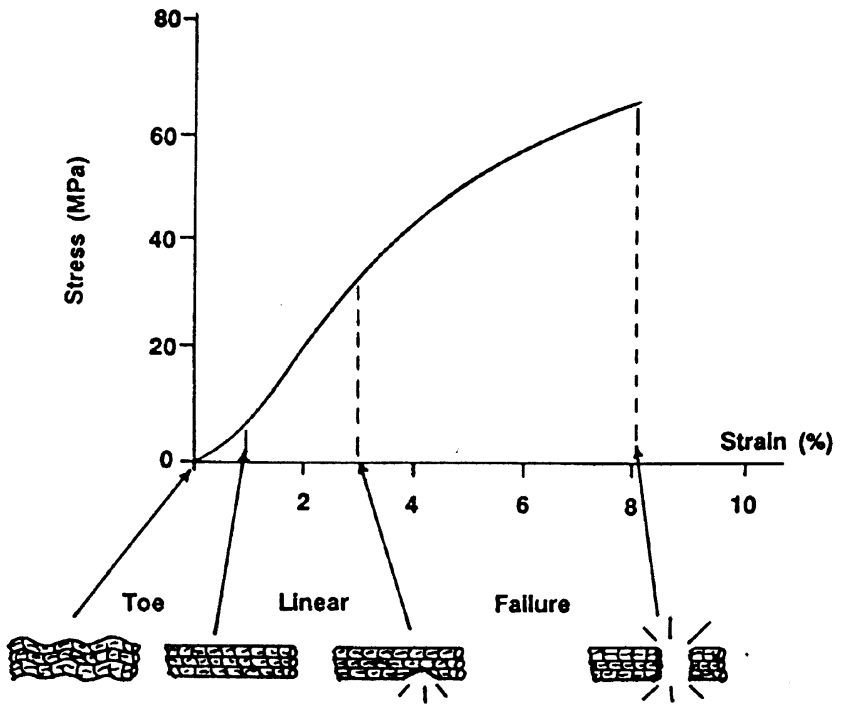

Figure I

Stress-strain relationship of the ligaments [I].

tearing in which the fibers of the ligament pull apart in the tissue, generally during a fast loading rate. The second mode is ligament-bone interface failure in which the fibers fail at the ligament-bone insertion without fracture of the underlying bone. The final mode is tibia or femoral avulsion fractures, usually occurring during relatively slow loading rates $[1,2]$.

Ligaments and bone have nonlinear time and history-dependent viscoelastic properties. These properties can be expressed in terms of stress-strain relationships with rate as an additional parameter. Figure 1 and 2 show typical stress-strain relationships of the ligament and bone respectively. For the ligament the slope of the stress-strain curve becomes nearly constant in the prefailure phase. The curve is composed of four regions; toe, linear, failure, and complete failure [1-4]. The ligament failure mode varies with different types of ligament (ACL, PCL, MCL, and LCL) due to their different viscosities [5]. Bone also has non-linear behavior and the elastic modulus is higher in bone than in ligament [6].

Stress (MPa), $\sigma$, is defined as the intensity of internal force over the unit cross-sectional area of the original specimen [1]. The definition of strain (\% or $\mathrm{m} / \mathrm{m}), \varepsilon$, is the change in length of the specimen, divided by its initial length [1]. Strain with percentage units is obtained by multiplying the $\mathrm{m} / \mathrm{m}$ form by 100 . The strain rate represents the change in elongation with time [4]. The extension or deformation rate $(\mathrm{m} / \mathrm{sec})$ of the specimen divided by its initial length $(\mathrm{m})$ gives the strain rate, as does the rate of change of the strain itself ( $\mathrm{d} \varepsilon / \mathrm{dt}$ ). Its unit is \%/sec (or simply $\sec ^{-1}$ ). Unfortunately not all of these parameters, or overall dimensions, are always given so that reported deformation rates cannot be converted into strain rates or vice versa. In addition, strain rates data alone does not allow calculations of failure load, since neither direct force nor effective mass are typically reported.

The electronic version of Medline was used to identify articles for this review. The keywords used for were strain rate, knee injury, and ligament. From the result of this search all involving strain-rate experiments of the boneligament-bone complex were further considered. Papers with only one bone-ligament attachment were excluded, as were those with only relative strain rates. The selected papers were further limited to those reporting quantified strain rates and the specific nature of the failures.

There are many recent studies on the effect of the strain rate on the failure mode of the knee [7-15]. These are summarized in Table 1 . The results of most studies show that at low strain rates avulsion occurs at the ligament insertion site on the bone or the bone itself may fail. At high strain rate, it is generally reported that the ligament tears [7-15]. However, the definitions of a fast or slow rate, and the actual rate range covered in each study, are different. In addition, the orientation of the bone-ligament-bone complex during testing may also affect the results, but details of this orientation are not typically provided.

Viidik et al. studied the effects of training in a running machine on rabbits. They showed the weakest point in the tibia-ligament-femur system to be one of the bony attachments, most often the tibial one [7].

In 1974(a) Noyes et al. used rhesus monkeys to investigate the effect of strain rate changes on the failure mode. The approximate strain rates were $0.62 \% / \mathrm{sec}^{-1}$ at the slow rate

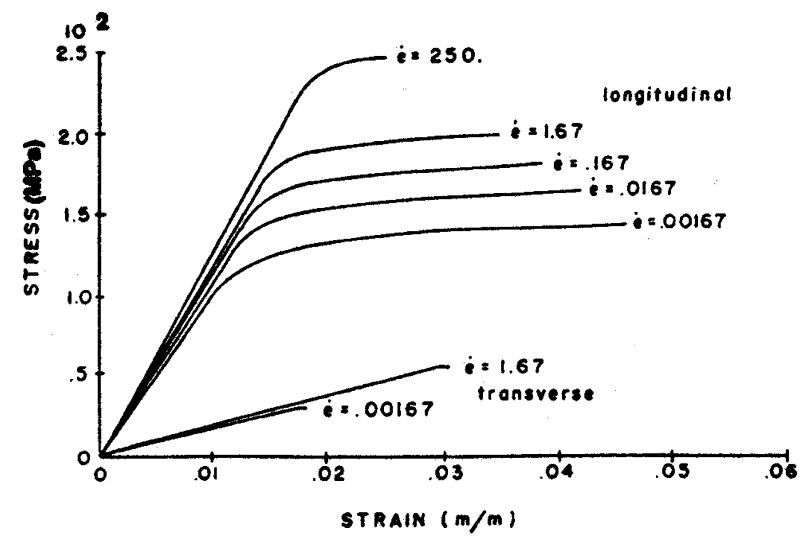

Figure 2

Stress-strain relationship of compact bovine bone [5]. 
Table I: The studies of the strain rate effect on the failure mode of the knee.

\begin{tabular}{|c|c|c|c|c|c|c|c|}
\hline Year & Author & Specimen & Strain rate & No. of knees & $\begin{array}{l}\text { Ligament } \\
\text { tearing }\end{array}$ & $\begin{array}{l}\text { Avulsion \& } \\
\text { Tearing }\end{array}$ & Avulsion \\
\hline \multirow[t]{2}{*}{1968} & Viidik et al & $\begin{array}{l}\text { White rabbits Femur-ACL-Tibia } \\
\text { Rotated medially } 90^{\circ} \text { Control }\end{array}$ & Not specified & 21 & 2 & 4 & 15 \\
\hline & & 40 weeks training & & 23 & 2 & 2 & 19 \\
\hline \multirow[t]{2}{*}{$1974 \mathrm{a}$} & Noyes et al & $\begin{array}{l}\text { Rhesus monkeys Femur-ACL-Tibia } 45^{\circ} \\
\text { flexion }\end{array}$ & Slow $0.62 \% / \mathrm{sec}$ & 28 & 8 & 4 & 16 \\
\hline & & & Fast $67 \% / \mathrm{sec}$ & 32 & 21 & 2 & 9 \\
\hline \multirow[t]{4}{*}{$1974 \mathrm{~b}$} & Noyes et al & $\begin{array}{l}\text { Rhesus monkeys Femur-ACL-Tibia } 45^{\circ} \\
\text { flexion Control }\end{array}$ & $66.2 \% / \mathrm{sec}$ & 30 & 18 & 3 & 9 \\
\hline & & 8 weeks immobilized & $66.2 \% / \mathrm{sec}$ & 18 & 8 & 3 & 7 \\
\hline & & Exercise & $66.2 \% / \mathrm{sec}$ & 22 & 10 & 4 & 8 \\
\hline & & Recondition & $66.2 \% / \mathrm{sec}$ & 22 & 14 & 2 & 6 \\
\hline 1974 & Alm, et al & $\begin{array}{c}\text { Beagle dogs Femur-ACL-Tibia } 90^{\circ} \\
\text { deflect }\end{array}$ & $\begin{array}{l}\text { Deformation } \\
\text { rate } 15 \mathrm{~mm} / \mathrm{sec}\end{array}$ & 80 & 75 & 5 & 0 \\
\hline \multirow[t]{4}{*}{1976} & $\begin{array}{l}\text { Crownishiel, } \\
\text { et al }\end{array}$ & Rat Femur-MCL-Tibia & $8.45^{*} 10-2 \% / \mathrm{sec}$ & 14 & 0 & 1 & 13 \\
\hline & & & $84.5 \% / \mathrm{sec}$ & 12 & 4 & 2 & 6 \\
\hline & & & $19000 \% / \mathrm{sec}$ & 16 & 8 & 4 & 4 \\
\hline & & & $51000 \% / \mathrm{sec}$ & 7 & 4 & 2 & 1 \\
\hline \multirow[t]{2}{*}{1976} & Kennedy, et al & $\begin{array}{c}\text { Human knee Femur-ACL-Tibia 20-75 } \\
\text { years }\end{array}$ & Slow $40 \% / \mathrm{sec}$ & 20 & 20 & 0 & 0 \\
\hline & & & Fast $140 \% / \mathrm{sec}$ & & & & \\
\hline \multirow[t]{3}{*}{1976} & Noyes, et al & $\begin{array}{c}\text { Human cadaver knee Older (48-86 } \\
\text { years) Femur-ACL-Tibia }\end{array}$ & $100 \% / \mathrm{sec}$ & 20 & 3 & 0 & 17 \\
\hline & & $\begin{array}{c}\text { Human cadaver knee Younger (16-26 } \\
\text { years) }\end{array}$ & $100 \% / \mathrm{sec}$ & 6 & 6 & 0 & 0 \\
\hline & & Rhesus monkeys ( 15 years) & $66 \% / \mathrm{sec}$ & 25 & 25 & 0 & 0 \\
\hline \multirow[t]{9}{*}{1990} & Woo et al & Immature rabbit Femur-MCL-Tibia & $0.011 \% / \mathrm{sec}$ & 18 & 0 & 0 & 18 \\
\hline & & & $0.15 \% / \mathrm{sec}$ & & & & \\
\hline & & & $1.59 \% / \mathrm{sec}$ & & & & \\
\hline & & & $\begin{array}{l}12 \% / \mathrm{sec} \\
155 \% / \mathrm{sec}\end{array}$ & & & & \\
\hline & & Mature rabbit Femur-MCL-Tibia & $0.011 \% / \mathrm{sec}$ & 18 & 12 & 6 & 0 \\
\hline & & & $0.15 \% / \mathrm{sec}$ & & & & \\
\hline & & & $1.66 \% / \mathrm{sec}$ & & & & \\
\hline & & & $18.6 \% / \mathrm{sec}$ & & & & \\
\hline & & & $222 \% / \mathrm{sec}$ & & & & \\
\hline \multirow[t]{4}{*}{1999} & Schenck et al & $\begin{array}{l}\text { Human cadaver knee Femur-PCL-Tibia } \\
45^{\circ} \text { hyper-extension Aver. } 61 \text { years }\end{array}$ & Slow $100 \% / \mathrm{sec}$ & 9 & 8 & 0 & 1 \\
\hline & & & Fast $5400 \% / \mathrm{sec}$ & 9 & 0 & 0 & 9 \\
\hline & & Femur-ACL-Tibia Aver. $6 \mathrm{I}$ years & Slow $100 \% / \mathrm{sec}$ & 9 & 5 & 4 & 0 \\
\hline & & & Fast $5400 \% / \mathrm{sec}$ & 9 & 4 & 2 & 3 \\
\hline
\end{tabular}

and $67 \% / \mathrm{sec}^{-1}$ at the fast rate. Ligament tearing happened more at the fast strain rate, with bone avulsion occurring more at the slow strain rate [8]. They also analyzed the effects of activity on ligament failure using the strain rate of $66.2 \% / \mathrm{sec}[9]$. This study showed $60 \%$ ligament tearing in the control group, 44\% ligament tearing and 39\% bony avulsion with 8 weeks of immobilization, $45 \%$ ligament tearing and $36 \%$ bony avulsion from an exercise group, and $65 \%$ ligament tearing from a reconditioning group [9].
Alm et al. used a $15 \mathrm{~mm} / \mathrm{sec}$ deformation rate on Beagle dogs to study the strength of the ACL. The mid part of the ligament ruptured in $93.7 \%$ of the tests [10].

Crownishield et al. tested failure characteristics of the MCL of rats at strain rates of $8.45^{*} 10^{-2}, 84.5,19000$, and $51000 \% / \mathrm{sec}$. As the strain rate increased, ligament tearing occurred more than avulsion. These authors described the range of injury strain rates in man as from approximately $50 \% / \mathrm{sec}$ to $150,000 \% / \mathrm{sec}[11]$. 
Kennedy et al. conducted ultimate failure strengths of the ACL at the strain rates of 40 , and $140 \% / \mathrm{sec}$. The ages of the human specimens ranged from 20 to 75 years, with a mean of 62 years. The major mode of failure was ligament tearing at both of the strain rates. [12].

In 1976 Noyes et al. evaluated the strength of the ACL in humans and rhesus monkeys to analyze age and species related changes. The age range of the human specimens was from 48 to 86 years for an older group, and from 16 to 26 years for a younger group. The rhesus monkeys were 15 years old. For the human specimens a strain rate of $100 \% / \mathrm{sec}$ was used for both old and young specimens. A strain rate of $66 \% / \mathrm{sec}$ was used for the monkeys. Ligament tearing was predominant in the specimens from younger humans and from rhesus monkeys. Avulsion of bone beneath the ligament insertion site was seen for the older humans [13].

Woo et al. studied the effect of strain rate on MCL failures in skeletally immature and mature rabbits. The range of strain rate used was from 0.011 to $222 \% / \mathrm{sec}$. Tibia avulsion developed in all specimens from skeletally immature rabbits with the strain rate from 0.011 to $155 \% / \mathrm{sec}$. Results for this group were not reported above $155 \% / \mathrm{sec}$. However, ligament tearing occurred from skeletally mature rabbits with the strain rate from 0.011 to $222 \% / \mathrm{sec}$ [14].

Schenck et al. investigated two "clinically applicable" stain rates, 100 and $5400 \% / \mathrm{sec}$ to study human ACL and PCL hyperextension. In the PCL, ligament tearing occurred at the lower stain rate, where as bone avulsion occurred at the higher strain rate. The order of these results is contrary to that of most of the other studies. In the ACL, the major failure mode at the low stain rate was similar to the PCL, with a mixed failure pattern at the higher strain rate [15].

The scope of these studies covers a very wide range of strain rates, multiple species, various ages, and in some cases direct intervention. Given this diverse set of results, a mathematical model of ligament and bony insert behavior was developed to provide an integrated understanding of the reported variations in failure mode.

\section{Methods}

Qualitative

We present a qualitative analytical model to analyze and explain these various results. The model takes into account the individual rate sensitivity of the strength of both the ligament and the bony insertion points. This provides an integrated view of the strength and failure mode of the combined system. As the strain rate increases, the stiffness and peak failure loads of the ligament and bone both increase $[1,3,16]$. Fig. 3 shows the relationship between the ultimate stress and strain for bone alone and ligament alone with loading rates. While the exact mechanisms of these changes are not well understood, the effect of strain rate on the stress-strain curves is produced in part by internal viscosity and energy dissipation [2]. Individually, these properties can be viewed as providing a protective mechanism under many circumstances in that they make the joint stiffer and stronger at high loading rates, at least up to their strength limits. When reported failure modes are considered for the bone-ligament-bone complex, the effect of the changing strain rate on the bone must be greater than that on the ligament.

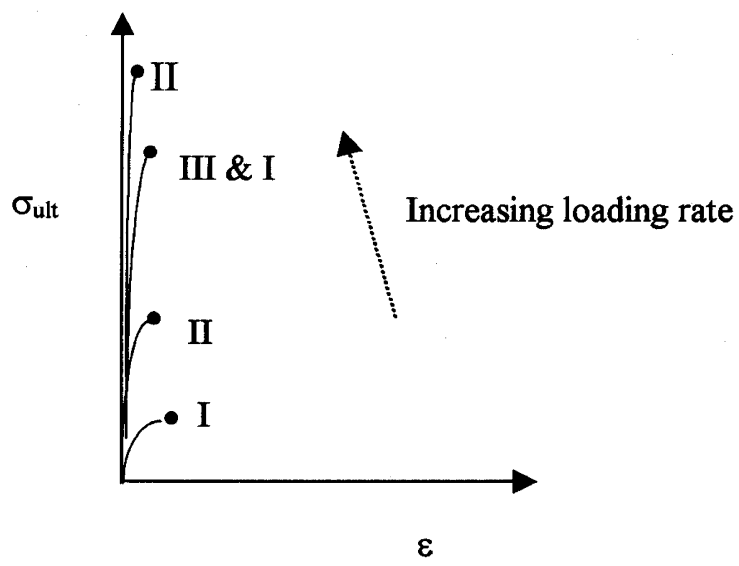

Bone

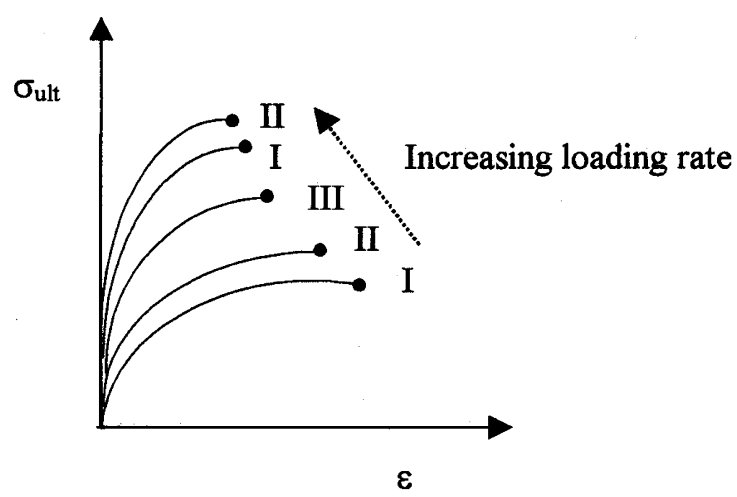

Ligament

Figure 3

Relationship between stress and strain for bone alone and ligament alone with loading rates. I, II, III, I and II correspond to failure modes. 
Failure mode I represents the situation in which bone avulsion occurs preferentially over ligament tearing. The ultimate failure stress of both bone and ligament $\left(\sigma_{\mathrm{ult}, \mathrm{B}}\right.$ $\sigma_{\mathrm{ult}, \mathrm{L}}$ ) is relatively small at these strain rates compared to the strengths at higher loading rates. The strength of the ligament at these rates is generally greater than the strength of bone. Therefore, the bony avulsion failure is more common at low strain rates because the bone failure point is reached first. The use of stress as the controlling parameter is based on the assumption of a ligament of uniform area and an equal effective bone insertion area. Alternatively the discussion could be based on load rather than stress, without changing the general argument.

Failure mode II is the case of bony avulsion or ligament tearing occurring at similar frequency, i.e., where the ultimate stress of bone and ligament are similar across the population. This mode occurs at higher strain rates than those of mode I. While both ligament and bone insertion strengths are larger than those in mode I at these larger stain rates, the strengths of the ligament and the insertion approach equality. Because there is not a clearly preferred type of failure in mode II, which failure occurs is likely defined more by individual variation than by fundamental biomechanics.

Failure mode III occurs at higher strain rates in which ligament tearing predominates over bone avulsion. As the strain rate increases further above that of mode II, the ultimate stress of bone and ligament continue to increase, but now the strength of the bone becomes stronger than that of the ligament [1-3].

When the strain rate increases overwhelmingly over that of mode III, the ultimate stress of bone stays about the same as in mode III but the ultimate stress of the ligament increases over that of mode III. Failure mode I show again. Also, failure mode II represents as the strain rate increases more than that of mode I. Fig. 4 represents modes I, II, III, I, and II.

\section{Quantitative}

We use the Kelvin model as a conceptual representation for describing the individual behavior of both the ligament and the bone as a function of loading rate. The Kelvin model is composed of a spring and dashpot element arranged in parallel (Fig. 5).

The total stress in each system is

$$
\begin{aligned}
& \sigma_{B}(t)=\sigma_{E, B}+\sigma_{\eta, B}=E_{B} \varepsilon_{B}(t)+\eta_{B} \dot{\varepsilon}_{B}(t) \\
& \sigma_{L}(t)=\sigma_{E, L}+\sigma_{\eta, L}=E_{L} \varepsilon_{L}(t)+\eta_{L} \dot{\varepsilon}_{L}(t)
\end{aligned}
$$

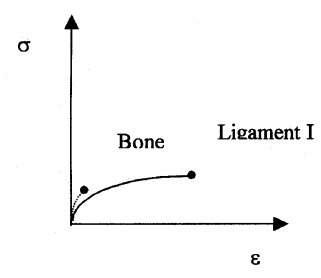

Mode I. Avulsion > Ligament tearing

$\sigma$

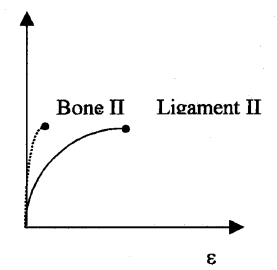

Mode II. Avulsion $\approx$ Ligament tearing

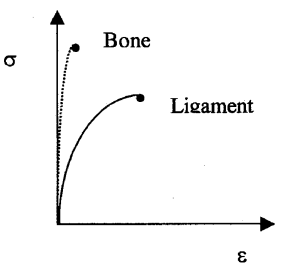

Mode III. Avulsion $<$ Ligament tearing

\section{Figure 4}

Failure Modes I, II, III, I, and II.

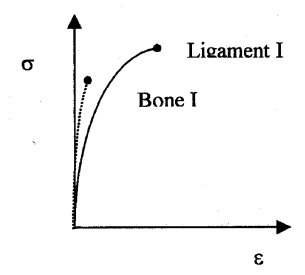

Mode I. Avulsion > Ligament tearing

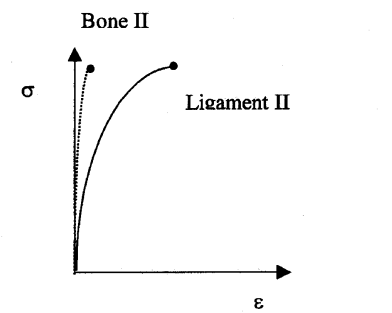

Mode II. Avulsion $\approx$ Ligament tearing where $E$ is the respective Young's modulus or the modulus of elasticity, $\eta$ is the respective coefficient of viscosity, and $\varepsilon(t), \varepsilon(t)$ are the respective strains and strain rates.

To model the effect of constant strain rate, $\varepsilon_{L}(t)$ is set to a constant value denoted by . From this, equation (2) can be written as

$\sigma_{L}(t)=E_{L} \varepsilon_{0} t+\eta_{L}$

Fig. 6 represents that stress and strain in the ligament have a linear relationship under the conditions shown in equation (3). While this is not the usually quoted result, it must be remembered that here this is under the specific condition of constant strain rate loading. When the strain rate increases the slope of this curve also increases. These equations describe the effect of strain rate on ligament 


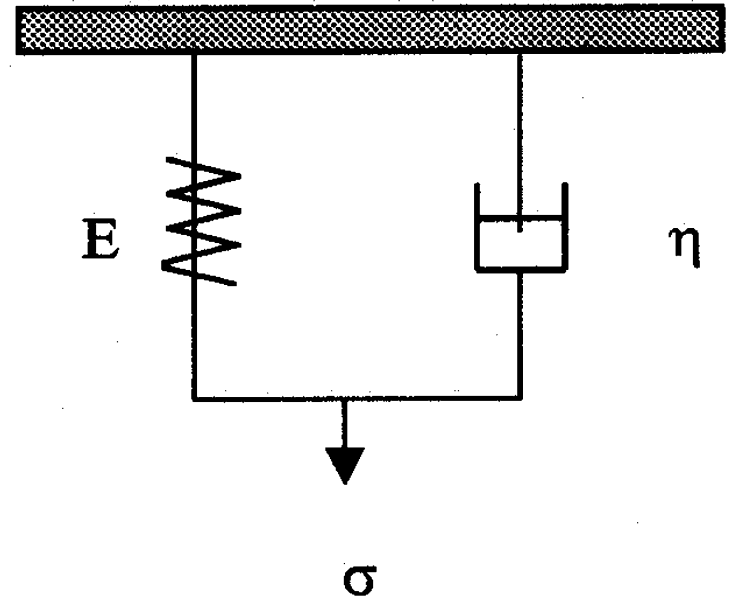

Figure 5

Kelvin model.

performance, although a failure point still has to be specified.

Neglecting the inertia term for the ligament, a balance of forces requires that the bone stress $\sigma_{\mathrm{B}}(t)$ be equal to the ligament stress $\sigma_{\mathrm{L}}(t)$ for constant area. Therefore, it is possible to solve for the strain $\varepsilon_{\mathrm{B}}(t)$ from equation (3) and (1).

$$
\begin{gathered}
\varepsilon_{B}(t)+\frac{E_{B}}{\eta_{B}} \varepsilon_{B}(t)=\frac{E_{L} t+\eta_{L} \varepsilon_{0}}{\eta_{B}}(4) \\
\varepsilon_{B}(t)=\left(\frac{E_{L} \varepsilon_{0}}{E_{B}} t\right)+\left(\frac{\eta_{L}}{E_{B}}-\frac{E_{L} \eta_{B}}{E_{B}^{2}}\right)
\end{gathered}
$$

While the strain $\varepsilon_{\mathrm{L}}(t)$ is only the given function of time, the strain $\varepsilon_{\mathrm{B}}(t)$ is a function of time and constant terms related to both bone and ligament properties.

\section{Results}

The failure modes were used to analyze the studies of Table 1 and restate the results as shown in Table 2 .

In Viidik, et al the failures are predominately mode I. Even though training had some positive effect on insertion point strength, this effect was not great enough to make $\sigma_{\mathrm{ult}, \mathrm{B}}>\sigma_{\mathrm{ult}, \mathrm{L}}$ and therefore avulsion remained the primary cause of failure.
Noyes, et al in 1974a, and 1974b, studied the ACL failure mode of Rhesus monkeys. The first study shows mode I at slow strain rate and mode III at fast strain rate. The mixed results suggest operation in the mode II region with significant individual variability. In the second Noyes, et al's study mode III predominates. Assuming immobilization reduces strength, $\sigma_{\text {ult, B }}$ reduced more than $\sigma_{\mathrm{ult}, \mathrm{L}^{\prime}}$ so that they approached equality. In exercise, either $\sigma_{\mathrm{ult}}, \mathrm{B}$ and $\sigma_{\text {ult, L }}$ is not significantly affected, or they both may increase without significant relative changes. In the latter case the analysis is limited by the lack of information actual failure loads or stresses. Even though changing their relative value, this effect is consistent with Viidik, et al. The reconditioning after immobilization suggest that reconditioning has a much greater effect on $\sigma_{\text {ult, } L}$ such that $\sigma_{\text {ult, }}$ L comes to exceed $\sigma_{\text {ult, B }}$ and the failure changes to mode III. Fig. 7 illustrates the changed in the ultimate stress of bone and ligament depending on the effect of activity as reported by Noyes, et al (1974b)

Kennedy, et al and Noyes, et al in 1976 studied ACL failure in human specimens. Even though different strain rates were used, mode III applies to both strain rates in Kennedy. In the age range from 20 to 75 years, $\sigma_{\text {ult, } \mathrm{B}}>$ $\sigma_{\text {ult, } L}$. The strain rates used don't affect the relative value of $\sigma_{\mathrm{ult}, \mathrm{B}}$ and $\sigma_{\mathrm{ult}, \mathrm{L}}$. However, we have different results in Noyes, et al's study. The older (48-86 years) and younger group (16-26 years) data fit mode I with $\sigma_{\mathrm{ult}, \mathrm{B}}<\sigma_{\mathrm{ult}, \mathrm{L}}$ and III with $\sigma_{\mathrm{ult}, \mathrm{B}}>\sigma_{\mathrm{ult}, \mathrm{L}}$ respectively. Assuming aging reduces strength, $\sigma_{\text {ult, B }}$ reduced more than $\sigma_{\text {ult, } L}$. The Rhesus monkeys group had the same failure mode as the younger group. These results demonstrate that strain rate alone is not the defining parameter. Analytically this

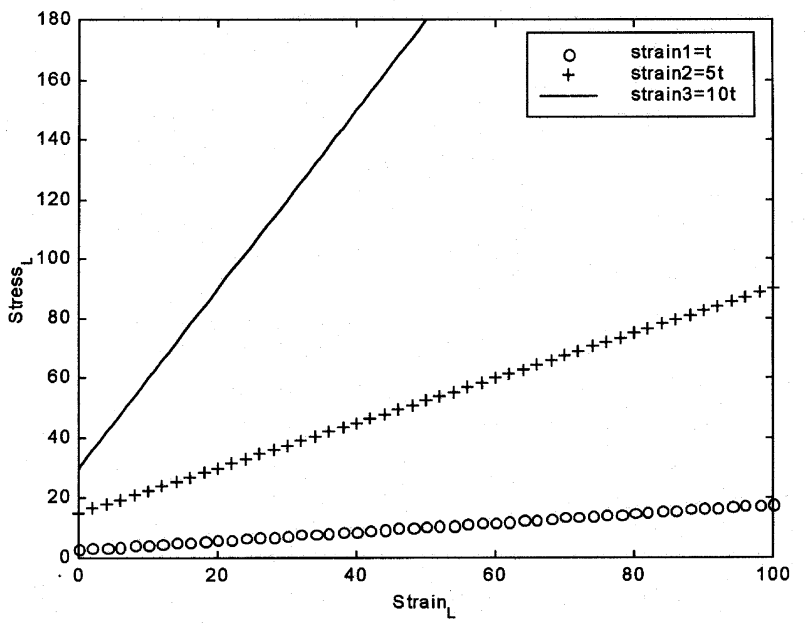

Figure 6

Relationship between stress and strain in the ligament is linear under the conditions shown in equation (3). 
Table 2: The failure mode results.

\begin{tabular}{|c|c|c|c|c|}
\hline Author & Failure mode & Ligament tearing & Avulsion \& Tearing & Avulsion \\
\hline \multirow[t]{2}{*}{ Viidik, et al } & $\mathbf{I}$ & $10 \%$ & $19 \%$ & $71 \%$ \\
\hline & I & $9 \%$ & $9 \%$ & $82 \%$ \\
\hline \multirow[t]{2}{*}{ Noyes, et al 1974a } & $\mathbf{I}$ & $29 \%$ & $14 \%$ & $57 \%$ \\
\hline & III & $66 \%$ & $6 \%$ & $28 \%$ \\
\hline \multirow[t]{4}{*}{ Noyes, et al I974b } & III & $60 \%$ & $10 \%$ & $30 \%$ \\
\hline & II & $44 \%$ & $17 \%$ & $39 \%$ \\
\hline & II & $45 \%$ & $18 \%$ & $36 \%$ \\
\hline & III & $64 \%$ & $9 \%$ & $27 \%$ \\
\hline Alm, et al & III & $94 \%$ & $6 \%$ & $0 \%$ \\
\hline \multirow[t]{4}{*}{ Crownishiel, et al } & I & $0 \%$ & $7 \%$ & $93 \%$ \\
\hline & | or || & $33 \%$ & $17 \%$ & $50 \%$ \\
\hline & III & $50 \%$ & $25 \%$ & $25 \%$ \\
\hline & III & $57 \%$ & $29 \%$ & $4 \%$ \\
\hline Kennedy, et al & III & $100 \%$ & $0 \%$ & $0 \%$ \\
\hline \multirow[t]{3}{*}{ Noyes, et al 1976} & $\mathbf{I}$ & $15 \%$ & $0 \%$ & $85 \%$ \\
\hline & III & $100 \%$ & $0 \%$ & $0 \%$ \\
\hline & III & $100 \%$ & $0 \%$ & $0 \%$ \\
\hline \multirow[t]{2}{*}{ Woo, et al } & I & $0 \%$ & $0 \%$ & $100 \%$ \\
\hline & III & $67 \%$ & $33 \%$ & $0 \%$ \\
\hline \multirow[t]{4}{*}{ Schenck, et al } & III & $89 \%$ & $0 \%$ & $11 \%$ \\
\hline & IV & $0 \%$ & $0 \%$ & $100 \%$ \\
\hline & III & $56 \%$ & $44 \%$ & $0 \%$ \\
\hline & $\mathbf{v}$ & $44 \%$ & $22 \%$ & $33 \%$ \\
\hline
\end{tabular}

would be reflected by $\mathrm{E}, \eta$, and $\sigma_{\mathrm{ult}}$ being a function of age and other conditions.

In Crownishield, et al's rabbit specimens, like Noyes, et al's study, increasing the strain rate caused a shift from mode I, to II, to III. The MCL study of Woo et. al is similar to Crownishield et. al except for the range of strain rate. Mode I applies to the immature group for all strain rates and mode III to mature group for all strain rates. Maturing increases strength, presumably more so for bone than ligament, and causing $\sigma_{\mathrm{ult}, \mathrm{B}}>\sigma_{\mathrm{ult}, \mathrm{L}}$. The effect of the strain rates used in each group is not seen, probably because they are not sufficiently different.

Schenck, et al reported their results as different from previous studies, but this is not clear given the variation in specimens and strain rates used. Therefore, the results of the effect of strain rate for the PCL and ACL were reverse from those of the previous studies, using strain rates intended to correlate differences between sporting and trauma [15]. However, only one other study, Crownnishield, et al using the rat MCL, used strain rates as high or higher than Schenck, et al's "fast" rate. Accepting that the rate and human results are consistent, Schenck et al's results suggest that the relative effect of stain rate on strength has a second cross over point. Fig. 8 shows this relationship.

\section{Discussion}

The effect of the strain rate on the failure modes of the bone-ligament-bone complex is an important factor in knee joint injury. We have defined five ranges of failure as a function of strain rate and other parameters. Avulsion happens more than ligament tearing in mode I which is

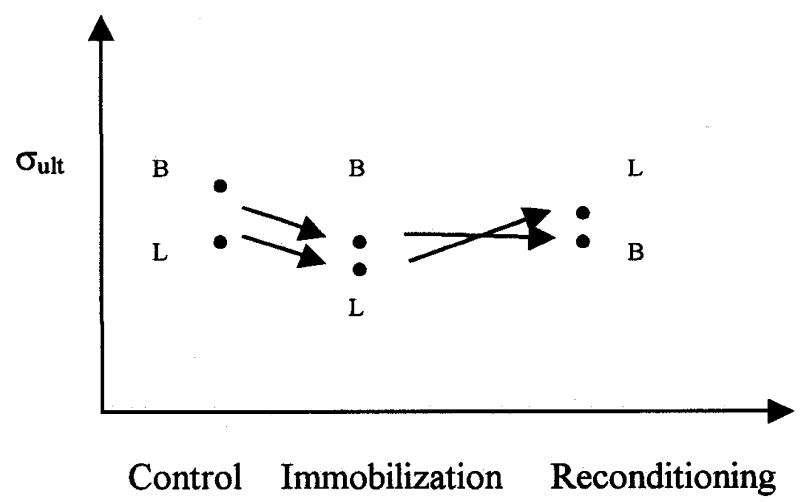

Figure 7

The ultimate stress of bone and ligament depending on the effect of activity as reported by Noyes et al (1974b). 


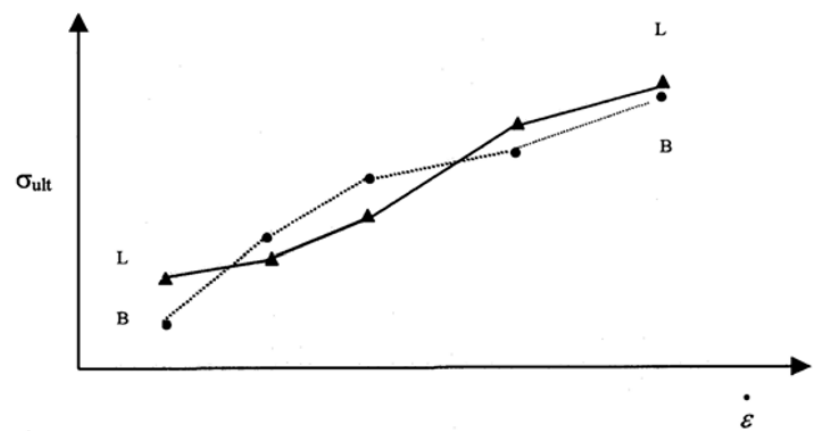

Mode I Mode II Mode III Mode I Mode II

\section{Figure 8}

Ultimate stress of mode I, II, III, I, and II.

primarily associated with low strain rates. The number of avulsion is comparable with the number of ligament tears in mode II, where individual variation is the dominant effect. Ligament tearing occurs more than bony avulsion in mode III that is associated with high strain rates. Finally, at very high strain rates the continued attraction in bone and ligament strength again, causes the ligament to become stronger than bone. Thus, mode I and mode II can be defined based on strain rates. The integrative concept for these failure modes is that both bone and ligament strengths increase with increasing strain rates, and that these are at least two points at which these functions cross. These results have important implications with respect to further experimental studies in this area. It is critical that strain rates be carefully defined, and that comparisons with other work be made on the basis of similar values, rather than just "high" and "low". Secondly, species, age, condition and other variables compound the difficulty of drawing broad conclusions, as does the lack of detail on orientation of the bone-ligament-bone complex during testing.

\section{References}

I. Hawkins D: Ligament Biomechanics. Current Issues in Biomechanics. Mark D Ed. (Grabiner. Human Kinetics Publishers) 1993123-150

2. Mow VC, Ratcliffe A, Woo S L-Y: Biomechanics of Diarthrodial Joints. Springer-Verlag New York Inc. 1990, I:

3. Akeson WH, Woo S L-Y, Amiel D, Frank CB: The Chemical basis of tissue repair: The biology of ligaments. Rehabilitation of the Injured Knee. 198493-109

4. Butler DL, Grood ES, Noyes FR: Biomechanics of Ligaments and tendons. Exercise and sports science reviews 1978, 6:125-181

5. Pioletti DP, Rakotomanana LR, Benvenuti JF, Leyvraz PF: Viscoelastic constitutive law in large deformations: application to human knee ligaments and tendons. Journal of Biomechanics 1998, 3 ।:753-757

6. Crowninshield RD, Pope $\mathrm{MH}$ : The response of compact bone in Tension at Various Strain Rates. Annals of Biomedical Engineering 1974, 2:217-225

7. Viidik A: Elasticity and tensile strength of the Anterior Cruciate Ligament in Rabbits as influenced by Training. Acta. Physiol. scand. 1968, 74:372-380
8. Noyes FR, DeLucas JL, Torvik PJ: Biomechanics of Anterior Cruciate Ligament failure: An Analysis of Stain-Rate Sensitivity and Mechanisms of Failure in Primates. The Journal of Bone and Joint Surgery 1974, 56-A:236-253

9. Noyes FR, Torvik PJ, Hyde WB, DeLucas JL: Biomechanics of Ligament Failure II. An Analysis of Immobilization, Exercise and Reconditioning Effects in Primate. The Journal of Bone and Joint Surgery, 1974, 56-A: 1406-1418

10. Alm A, Ekstrom H, Stromberg B: Tensile Strength of the Anterior Cruciate Ligament in the Dog. Acta Chir. Scad. Suppl. 1974, 445: I5

II. Crownishield RD, Pope MH: The Strength and Failure characteristics of rate medical collateral ligaments. The Journal of Trauma 1976, I 6:99-105

12. Kennedy JC, Hawkins RJ, Willis RB, Danylchuk KD: Tension Studies of Human Knee Ligaments: Yield Point, Ultimate failure, and Disruption of the Cruciate and Tibial Collateral Ligaments. The Journal of Bone and Joint Surgery 1976, 58-A:350-355

13. Noyes FR, Grood ES: The Strength of the Anterior Cruciate Ligament in Human and Rhesus Monkeys: Age-related and Species-related Changes. The Journal of Bone and Joint Surgery December 1976, 58-A: I074-1082

14. Woo S L-Y, Peterson RH, Ohland KJ, Sites TJ, Danto MI: The Effects of Strain Rate on the Properties of the Medial Collateral Ligament in Skeletally Immature and Mature Rabbits: A biomechanical and Histological Study. Journal of Orthopaedic Research, I990, 8:7|2-72।

15. Schenck RC Jr, Kovach IS, Agarwal A, Brummett R, Ward RA: Cruciate Injury Patterns in Knee Hyperextension: A Cadaveric Model. Arthroscopy 1999, I 5:489-495

16. Pioletti DP, Rakotomanana LR, Leyvraz PF: Strain rate effect on the mechanical behavior of the anterior cruciate ligament bone complex. Medical Engineering \& Physics 1999, 2 1:95-100

Publish with BioMed Central and every scientist can read your work free of charge

"BioMedcentral will be the most significant development for disseminating the results of biomedical research in our lifetime." Paul Nurse, Director-General, Imperial Cancer Research Fund

Publish with BMC and your research papers will be:

- available free of charge to the entire biomedical community

- peer reviewed and published immediately upon acceptance

- cited in PubMed and archived on PubMed Central

- yours - you keep the copyright

Submit your manuscript here:

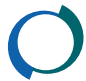

BioMedcentral.com

http://www.biomedcentral.com/manuscript/ 